\title{
Inulin Clearance in the Newborn Infant: Relationship to Gestational and Postnatal Age
}

\author{
ROSEMARY D. LEAKE, ${ }^{(18)}$ CARL W. TRYGSTAD, AND WILLIAM OH \\ Department of Pediatrics, UCLA School of Medicine, Harbor General Hospital, Torrance, California, USA
}

\begin{abstract}
Extract
Thirty-eight healthy newborn infants with gestational ages ranging from 25 to 42 weeks were studied at 2 days to 9 weeks postnatal age to evaluate the rate of glomerular maturation after birth. Glomerular function was assessed by a constant infusion method for inulin clearance $\left(C_{i n}\right) . C_{i n}$ was nearly identical when measured by the traditional clearance method and by the constant infusion technique. The $C_{\text {in }}$ of 22 infants $2-3$ days old ranged from 0.6 to 17.9 $\mathrm{ml} / \mathrm{min}$ and was directly related to gestational age $(r=0.81, P<$ 0.001 ). For 26 infants studied at $1-9$ weeks of age, $C_{i n}$ was directly proportional to conceptual (gestational and postnatal) age ( $r=\mathbf{0 . 8 9}$, $P<0.001)$, and approximated that of infants of similar gestational age studied at $2-3$ days of age.
\end{abstract}

\section{Speculation}

With the confirmation of the ease and accuracy with which $C_{i n}$ can be measured by the constant inulin infusion method, it should be possible to study glomerular filtration rate (GFR) under various clinical conditions, including very limited renal function. The lack of extrauterine acceleration of renal maturation which we have demonstrated may indicate an anatomic limitation in the first several months of life.

Although works in the past few decades have defined many developmental aspects of renal anatomy in infants (4), less is known regarding renal functional development. This is partly because of the technical impossibility of assessing renal function in utero in the human fetus and partly because conventional renal function studies require accurately timed urine collections which are difficult in the neonate without bladder catheterization. A simple constant infusion technique for inulin clearance, as described by Cole et al. (2) in older children, would seem useful for application in human neonates both for clinical and investigative studies of renal function. One objective of this report is to evaluate the validity of the constant inulin infusion technique for measuring glomerular filtration rate in the newborn.

Robillard et al. (8), utilizing an intrauterine fetal sheep preparation, has shown that actual values of GFR increase during the third trimester of pregnancy. They postulate that parallel increases in fetal weight and kidney weight may explain the absence of variation in ratio of GFR to fetal weight and GFR to kidney weight.

Studies in puppies have shown that renal blood flow increases rapidly after birth (7). It has also been shown that the glomerular epithelium becomes more permeable during the first few months, which may partly account for the development increment in GFR (10).

In humans, Oh et al. (6) have shown that the $\mathrm{C}_{i n}$ of term infants at $1-12 \mathrm{hr}$ of age averaged $20 \mathrm{ml} / \mathrm{min} / 1.73 \mathrm{~m}^{2}$, and that at $2-5$ days of age there is a significant increase to $33.0 \mathrm{ml} / \mathrm{min} / 1.73 \mathrm{~m}^{2}$.
Changes in GFR during postnatal life have been measured by Barnett et al. (1) who reported a higher inulin clearance in older premature infants. Vesterdal and Tudvad (11), on the other hand, show a similar $\mathrm{C}_{\mathrm{in}}$ in premature and term infants. Guignard (5) found a direct relationship between inulin clearance and postnatal age, but failed to show a relationship between GFR and gestational age when infants of 32-39 weeks of gestation were studied at 12-96 $\mathrm{hr}$ of age. Thus it appears that data on glomerular function in human infants are minimal and that the available data concerning functional development are somewhat confusing. In this report, we have attempted to measure the rate of maturation of glomerular function after birth by comparing inulin clearance in 2-3-day-old infants of a particular gestational age with that of 1-9-week-old infants of the same conceptual age (gestational age and postnatal age).

\section{METHODS AND MATERIALS}

Thirty-eight healthy, appropriate for gestational age, newborn infants were selected for the study. Mean birth weight was $1,780 \mathrm{~g}$ (range 545-3740 g). Gestational age, determined by menstrual history and by Dubowitz scoring (3), ranged from 25 to 42 weeks. Twenty-two infants were male and 16 were female. No significant prenatal or intrapartum complications were observed in the histories of 29 infants but the pregnancy was complicated by premature rupture of membranes in 5 cases, maternal amnionitis in 2, abruptio placenta in 1 , and maternal pneumonia at delivery in 1 case. Six infants had respiratory distress syndrome and four had meconium aspiration syndrome initially, but all were well at the time of study. Sixteen infants were receiving intravenous infusions of $100-150 \mathrm{ml} / \mathrm{kg} /$ day of $10 \%$ dextrose in water with maintenance sodium and potassium (2-3 mEq/ kg/day) on the day of study; 22 were taking $120-150 \mathrm{ml} / \mathrm{kg} /$ day of milk-based formula.

The infants were studied either at 2-3 days of age (mean age $=$ $68 \mathrm{hr}$, range $=50-80 \mathrm{hr})$ or at $1-9$ weeks of age $($ mean $=22.8$ days, range $=7-63$ days). The former studies were done to illustrate the glomerular function after initial hemodynamic adjustment had taken place after birth and the latter, the postnatal development of glomerular function. Ten infants were studied serially.

The protocol was approved by the Harbor General Hospital Committee on Human Use. After informed parental consent was obtained, an intravenous solution of $10 \%$ dextrose in water was administered at a rate of $6 \mathrm{mg}$ glucose $/ \mathrm{kg} / \mathrm{min}$ until the infant voided. A baseline serum inulin sample was obtained. A priming dose of $50 \mathrm{mg} / \mathrm{kg}$ body weight of inulin (12) (10\% solution) was infused intravenously over a 1 -min period. A sustaining dose of 0.1 $\mathrm{mg} / \mathrm{kg} / \mathrm{min}$ inulin and glucose was administered by means of a constant infusion pump (13) for $1-3 \mathrm{hr}$ using a $0.13 \%$ inulin and $10 \%$ glucose mixture. The mean duration of study was 74 min. Serial inulin samples were obtained by heel puncture every $30-45$ min and at the time of each voiding. Infusate concentration of inulin was measured. The pump infusion speed was determined at 
appropriate intervals. Inulin determinations were performed by the resorcinol method (9). A standard curve for inulin and serum blank were run with each determination. Inulin clearance was calculated on the basis of a constant infusion principle with the following formula:

inulin concentration in infusate $(\mathrm{mg} / \mathrm{ml})$ $\times$ rate of inulin infusion $(\mathrm{ml} / \mathrm{min})$

plasma inulin concentration $(\mathrm{mg} / \mathrm{ml})$

The constant infusion method for determining inulin clearance is based on the premise that the rate of inulin infusion aporoximates the rate of urinary excretion when a steady plasma level for inulin is reached. In 22 infants timed urine volumes and inulin concentrations were also determined to calculate the inulin clearance by the conventional technique, using the formula: $\mathrm{C}_{i n}=\mathrm{U}_{i n} \mathrm{~V} / \mathrm{P}_{i n}$, where $\mathrm{U}_{\mathrm{in}}=$ urinary inulin concentration, $\mathrm{V}=$ urine volume in milliliters per min, and $\mathrm{P}_{\mathrm{in}}=$ plasma inulin concentration. The values of $\mathrm{C}_{\mathrm{in}}$ obtained by conventional formula were compared with those obtained in the same infants and at the same time by the constant infusion method described above.

\section{RESULTS}

Figure 1 shows serial plasma inulin levels for the first 22 infants studied. Within $78 \mathrm{~min}$ after the priming inulin dose and the constant inulin infusion, a steady state of plasma inulin was reached for all infants included in the study.

Figure 2 shows that when results of inulin clearances obtained simultaneously by constant infusion and conventional methods in

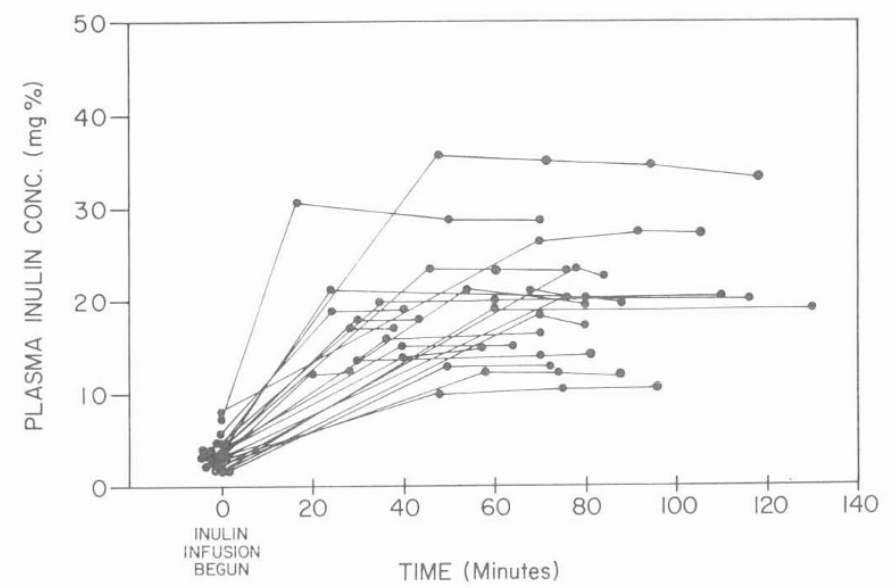

Fig. 1. Plasma inulin levels during constant inulin infusion.

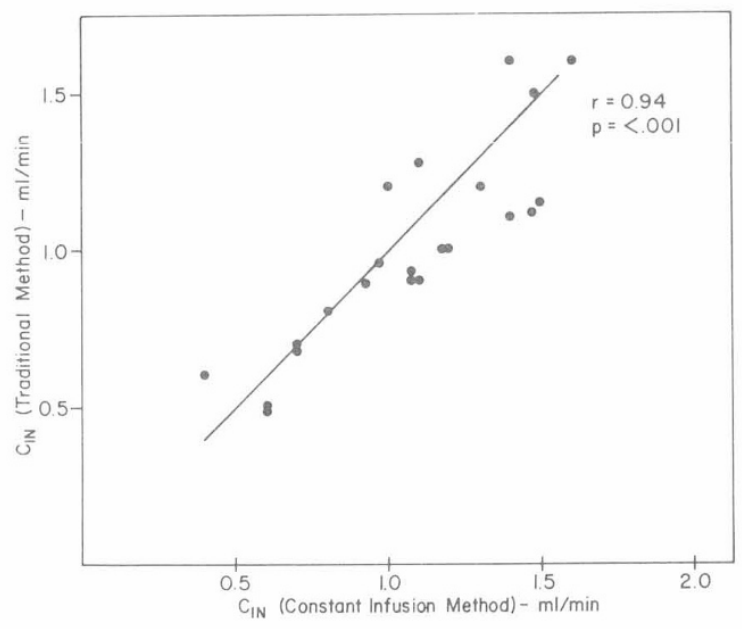

Fig. 2. Comparison of simultaneous determinations of inulin clearance by traditional and constant infusion methods.

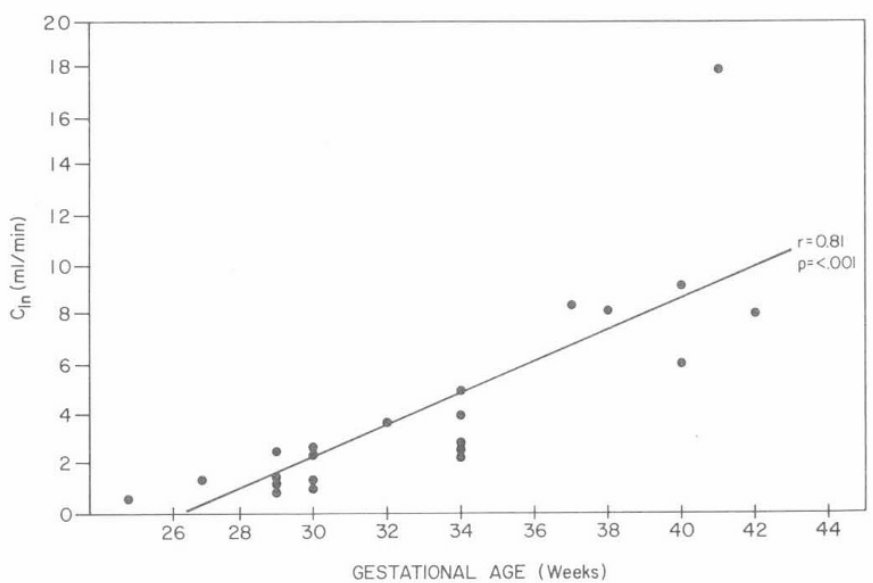

Fig. 3. $\mathrm{C}_{\text {in }}$ for 2-3-day-old infants at various gestationa ages.

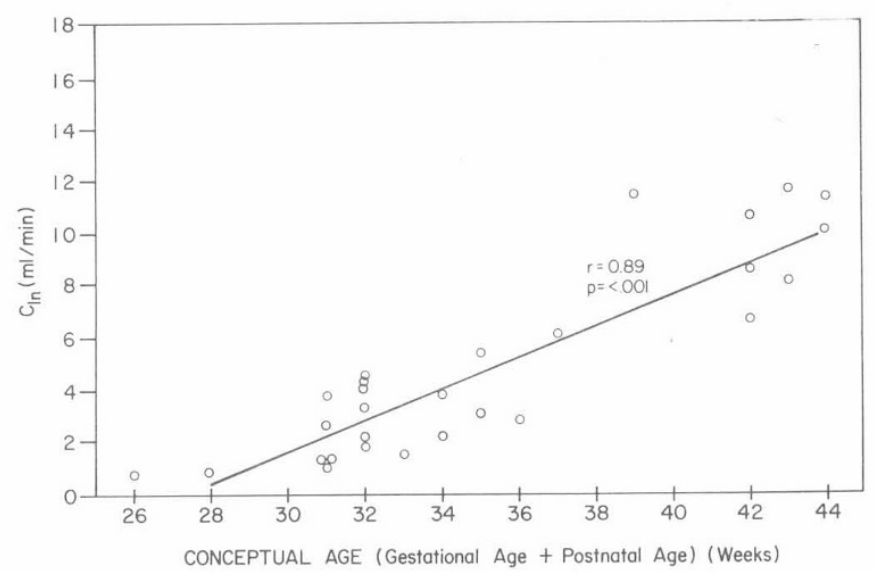

Fig. 4. $C_{\text {in }}$ for 1-9-week-old infants at various conceptual ages.

22 infants were compared, there was a correlation coefficient of $0.94(P<0.001)$, and the regression slope for these observations fell nearly on the line of identity.

The value of inulin clearance for the 22, 2-3-day-old infants varied from 0.6 to $17.9 \mathrm{ml} / \mathrm{min}$. As shown in Figure 3, a direct correlation was demonstrated when $\mathrm{C}_{\mathrm{in}}$ was plotted against gestational age $(r=0.81, P<0.001)$.

When 26 older infants varying in postnatal age from 1-9 weeks were studied, their $C_{i n}$ varied directly with conceptual age. The latter represents the sum of gestational age and postnatal age. A linear regression line for this relationship, shown in Figure 4, demonstrates a correlation coefficient of $0.89(P=<0.001)$, and could be nearly superimposed on the linear regression line for infants studied at 2-3 days of age. Thus an infant born at 32 weeks gestation studied 2 weeks after birth (conceptual age $=34$ weeks), had nearly the same $C_{i n}$ as another infant of 34 weeks' gestation studied at 2 days of age. The three cases where serial studies were performed after 1 week of age appear as separate points on Figurc 4. Table 1 shows the data for those infants studied serially. Table 2 shows the data for the 26 infants who were studied beyond 1 wer of age. $C_{i n}$ expressed as $\mathrm{ml} / \mathrm{min} / 1.73 \mathrm{~m}^{2}$ was also directl proportional to gestational age $(P<0.001)$.

\section{DISCUSSION}

Cole, in a study involving children varying in age from 1-17 years, has demonstrated that there is a close correlation between glomerular filtration rates determined by conventional and constant inulin infusion methods (2). Our study reports the first use of the constant inulin infusion technique for newborn infants. The 
Table 1. Inulin clearance for 10 infants studied serially

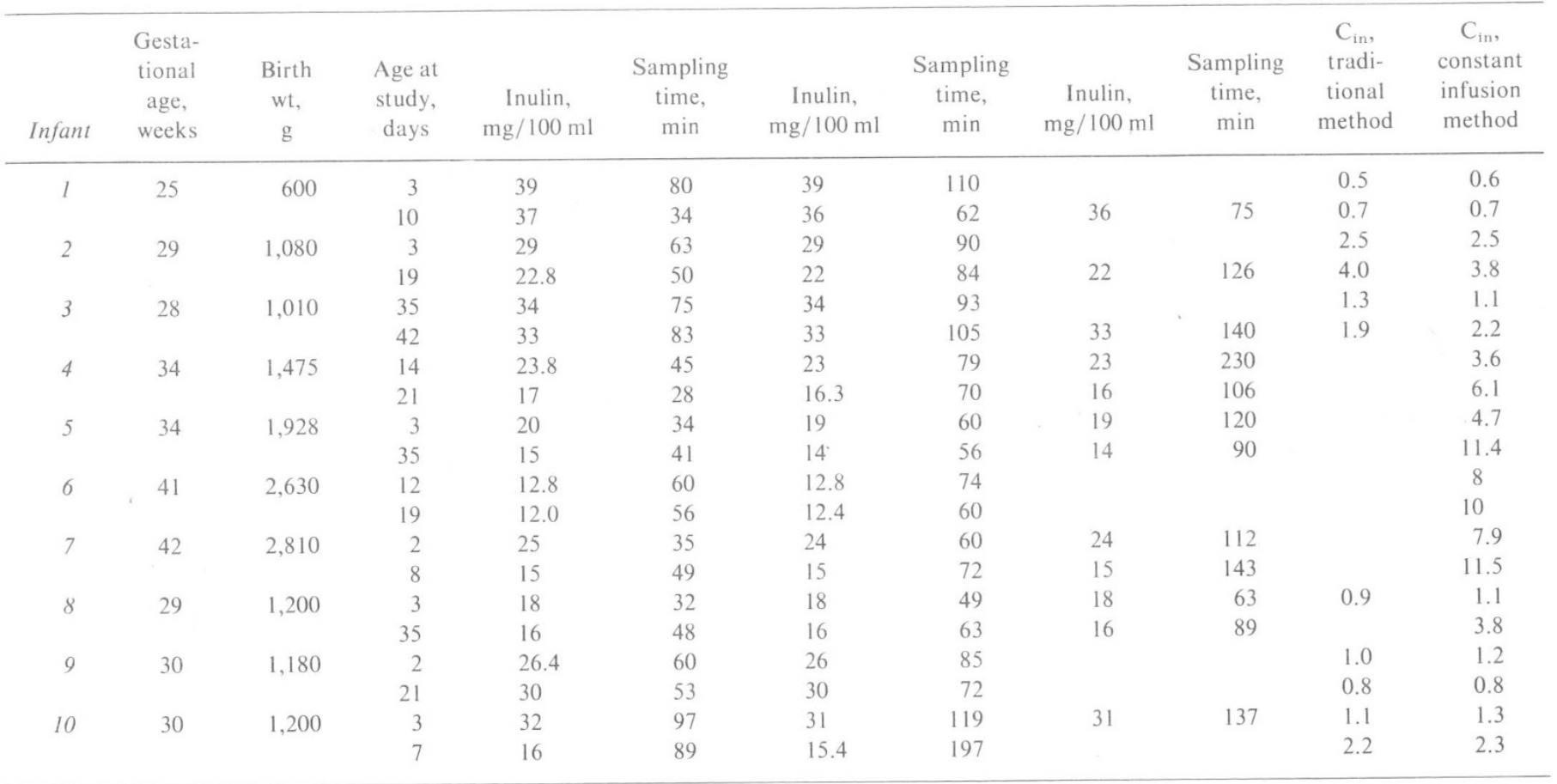

Table 2. Data for infants studied after I week of age

\begin{tabular}{|c|c|c|c|c|c|}
\hline \multirow[b]{2}{*}{ Study } & \multirow{2}{*}{$\begin{array}{l}\text { Gestational } \\
\text { age, weeks }\end{array}$} & \multirow{2}{*}{$\begin{array}{l}\text { Weeks at } \\
\text { study }\end{array}$} & \multirow{2}{*}{$\begin{array}{l}\text { Wt at } \\
\text { study }\end{array}$} & \multicolumn{2}{|r|}{$\mathrm{C}_{\text {in }}$} \\
\hline & & & & $\mathrm{ml} / \mathrm{min}$ & $\mathrm{ml} / \mathrm{min} / 1.73$ \\
\hline \multirow[t]{2}{*}{$l$} & 34 & 2 & 1,710 & 3.6 & 35 \\
\hline & & 3 & 2,030 & 6.1 & 70 \\
\hline 2 & 29 & 3 & 1,580 & 4.4 & 66 \\
\hline 3 & 26 & 9 & 1,220 & 5.3 & 77 \\
\hline 4 & 42 & 1 & 2,840 & 11.5 & 99 \\
\hline 5 & 29 & 5 & 1,270 & 3.8 & 56 \\
\hline \multirow[t]{2}{*}{6} & 41 & 2 & 2,630 & 8 & 74 \\
\hline & & 3 & 2,780 & 10 & 96 \\
\hline 7 & 29 & 3 & 1,060 & 3.8 & 60 \\
\hline 8 & 34 & 5 & 3,062 & 11.4 & 99 \\
\hline 9 & 29 & 2 & 1,310 & 1.3 & 19 \\
\hline \multirow[t]{2}{*}{10} & 28 & 5 & 1,030 & 1.1 & 22 \\
\hline & & 6 & 1,048 & 2.2 & 34 \\
\hline 11 & 30 & 1 & 1,000 & 2.3 & 40 \\
\hline 12 & 29 & 2 & 980 & 1.8 & 31 \\
\hline 13 & 28 & 7 & 1,940 & 3.4 & 37 \\
\hline 14 & 30 & 2 & 1,265 & 4.4 & 52 \\
\hline 15 & 29 & 2 & 700 & 0.89 & 1 \\
\hline 16 & 28 & 4 & 1,230 & 3.8 & 55 \\
\hline 17 & 31 & 3 & 1,820 & 2.2 & 24 \\
\hline 18 & 29 & 3 & 2,060 & 2.3 & 25 \\
\hline 19 & 30 & 2 & 1,310 & 2.0 & 19 \\
\hline$\therefore 20$ & 41 & 1 & 2,840 & 6.2 & 54 \\
\hline 21 & 40 & 2 & 2,985 & 8.4 & 72.6 \\
\hline$x=22$ & 38 & 4 & 3,010 & 11.0 & 95 \\
\hline 23 & 25 & 1 & 590 & 0.7 & 1 \\
\hline$? 4$ & 40 & 4 & 2,800 & 13.6 & 117 \\
\hline$? 5$ & 27 & 1 & 1,050 & 0.7 & 12 \\
\hline$? 6$ & 34 & 1 & 1,984 & 4.3 & 46 \\
\hline
\end{tabular}

Surface area unknown.

-esults showed that a close correlation exists between the two methods in neonates although the line of identity shown in Figure 2 demonstrates that the constant inulin method slightly overestimates inulin clearance in most cases. The constant infusion method does offer the distinct advantage of requiring no urine collection; hence, renal function studies can be performed with ease on small, sick, and/or oliguric newborns.

A steady state for inulin was achieved in a shorter period of time in our study than in studies of older subjects (2), perhaps because of the rapid circulation time and smaller overall total volume of distribution of newborns. The attainment of a constant plasma inulin level does not necessarily imply that the inulin infusion rate and renal excretion are equal. The extent of inulin re-entry from the interstitial spaces and extrarenal loss of inulin from plasma are not determined by this method.

Our inulin clearance data compare well with those found by previous investigators. When expressed on the basis of surface area, the inulin clearance in our series has a range of 12-117 $\mathrm{ml} / \mathrm{min} / 1.73 \mathrm{~m}^{2}$. Barnett et al. (1) described a mean GFR of 48 $\mathrm{ml} / \mathrm{min} / 1.73 \mathrm{~m}^{2}$ in eight infants from 3-13 days of age. They also compared the inulin clearance values of infants from 3-13 days with those of infants of similar weight at 49-107 days of age and report a mean value of 4.67 and $6.92 \mathrm{ml} / \mathrm{min}$, respectively. Thus Barnett's infants, studied for a longer period of time, achieved a greater $C_{i n}$ with greater postnatal age. Weight was used as the criterion for gestational age in his study; therefore, it is not certain how many of the study infants were small for gestational age. Vesterdal (11), describing the inulin clearance of infants from 1-118 days old, found no difference between the values of full term and premature infants weighing more than $1,500 \mathrm{~g}$.

Although Guignard (5) demonstrated a relationship between inulin clearance and postnatal age, he failed to find a relationship between inulin clearance and gestational age when infants of 12-96 hr of age were studied. Studies performed in the first few hours after delivery may more nearly reflect the functional status in utero. It has been shown that the $\mathrm{C}_{i n}$ values of term infants studied at $1-12 \mathrm{hr}$ of age are significantly lower than those values obtained when infants of similar gestational age were studied at 2-5 days of age. Our data support the concept that the rate of postnatal maturation is constant when measured at $2-3$ days of age $($ mean $=$ $68 \mathrm{hr}$ ) and weekly thereafter during the first 2 months of life. By that time extrauterine adaptation of renal function has taken place. An additional difference in our study and that of Guignard was our inclusion of infants between 25 and 32 weeks of gestation and the serial study of 10 infants. It is not surprising that there is a rapid increase in renal function from the first few hours to the second or 
third day of life since fetal excretory functions are performed mainly by the placenta with minimal contribution by the fetal kidney. After placental separation, a rapid increase in the renal circulation occurs over the first days of life (6). We have found that after an initial extrauterine adaptation of glomerular function in the first 2-3 days of life, no further functional acceleration occurs in the immediate postnatal period despite continued challenges imposed on the kidney during postnatal life.

Our findings of remarkably low $C_{i n}$ for the infants of 25-30 weeks' gestation point out the necessity for modifying fluid and drug administration to small premature infants, but add the encouraging note that even $545-\mathrm{g}$ infants have a predictable, sufficient glomerular filtration rate $\left(C_{i n}\right)$ for survival. It is not known whether the rate of maturation in the first few hours of life is as rapid for the markedly premature infant as that demonstrated in infants of higher gestational age. This aspect of ontogeny in renal function requires further investigation.

\section{SUMMARY}

The inulin clearances of 38 healthy infants varying in gestational age from 25 to 42 weeks were studied by the constant infusion method. The validity of the constant infusion for $C_{i n}$ was confirmed. Inulin clearance was directly proportional to gestational age when measured at 2-3 days of age. Inulin clearance was proportional to conceptual age (gestational age and postnatal age) when measured at 1-9 weeks of age. There was no functional acceleration of inulin clearance when infants of a particular gestational age studied at 2-3 days of life were compared with those attaining a similar conceptual age (gestational plus postnatal age).

Copyright ( 1976 International Pediatric Research Foundation, Inc.

\section{REFERENCES AND NOTES}

1. Barnett, H. L., Hare, W. K., McNamara, H., and Hare, R. S.: Influence of postnatal age on kidney function of premature infants. Proc. Soc. Exp. Biol. A. Med., 69: 55 (1948).

2. Cole, B. R., Giangiacomo, J., Ingelfinger, J., and Robson, A.: Measurement of renal function without urine collection. N. Engl. J. Med., 287: 1109 (1972).

3. Dubowitz, L. M., Dubowitz, V., and Goldberg, C.: Clinical assessment of gestational age in newborn infants. J. Pediat., 77 : 1 (1970).

4. Edelmann, Jr., C. M.: Pediatric nephrology. Pediatrics, 51: 854 (1973).

5. Guignard, J. P., Torrado, A., Da Cunha, O., and Gautier, E.: Glomerular filtration rate in the first three weeks of life. J. Pediat., 87: 268 (1975).

6. Oh, W., Oh, M. A., and Lind, J.: Renal function and blood volume in newborn infants related to placental transfusion. Acta Paediat. Scand., 56: 197 (1966).

7. Olbing, H., Blaufox, M. D., Aschinberg, L. C., Silkalns, G. I., Bernstein, J., Spitzer, A., and Edelmann, C. M., Jr.: Postnatal changes in renal glomerular blood flow distribution in puppies. J. Clin. Invest., 53: 2885 (1973).

8. Robillard, J. E., Kulvinskas, C., Sessions, C., Burmeister, L., and Smith, F. G.: Maturational changes in the fetal glomerular filtration rate. Amer. J. Obstet. Gynecol., 122: 601 (1975).

9. Roe, J. H., Epstein, J. H., and Goldstein, N. P.: A photometric method for the determination of inulin in plasma and urine. J. Biol. Chem., 178: 839 (1949).

10. Spitzer, A., and Brandis, M.: Functional and morphologic maturation of the superficial nephrons. J. Clin. Invest., 53: 279 (1974).

11. Vesterdal, J., and Tudvad, F.: Studies on the kidney function in premature and full term infants by estimation of the inulin and Para-aminohippurate clearance. Acta Paediat. Scand., 37: 429 (1949).

12. Purified Inulin Solution, Stone Arnar Company, Mt. Prospect, III.

13. Harvard Pump, Harvard Instrument Co.

14. The authors wish to thank Ruey-Yueh Ho for technical assistance in this study.

15. This paper was presented in part at the Society for Pediatric Research, Washington, D.C., May 3, 1974.

16. This research was supported in part by the General Research Support Grant P1549, National Institute of Health, Bethesda, Maryland.

17. The present address of Dr. W. Oh is: Women and Infants Hospital of Rhode Island, 50 Maude St., Providence, R.I. 02908 (USA).

18. Requests for reprints should be addressed to: R. D. Leake, M.D., Department of Pediatrics, Harbor General Hospital, 1000 W. Carson St., Torrance, Calif. 90509 (USA)

19. Accepted for publication February 17, 1976.

\title{
Child's Urinary Lithiasis Revealing a Complete Deficit in Adenine Phosphoribosyl Transferase
}

\author{
H. DEBRAY, ${ }^{11}$ P. CARTIER, A. TEMSTET, AND J. CENDRON \\ Hôpital Saint-Joseph, Service de Pediatrie, Paris, France
}

\section{Extract}

In one case of a urinary lithiasis, termed "uric lithiasis" on biochemical examination, the authors describe the symptomatology of a child with a complete deficit in adenine phosphoribosyl transferase. After more intensive investigation the calculi have been found to be composed of a new clinical compound: 2,8-hydroxyadenine.

\section{Speculation}

A diagnosis of infantile uric lithiasis should be accepted with certain reservations in the absence of a spectrophotometric examination of the calculus.
The pathogenesis of uric acid lithiasis, a rare disease in pediatrics, is uncertain. At Saint-Joseph's hospital in Paris, we observed a very young child with multiple recurring stones. After biochemical examination the stones were labeled as "uric lithiasis." This observation proved interesting for two reasons: it led to the discovery of a complete deficit of an enzyme associated with purine metabolism (APRTase). To our knowledge a complete deficit of APRTase has not been described. In addition, it led us to a more complete examination of the calculus by spectrophotometry. Our findings, to be described, indicate that a diagnosis of infantile uric lithiasis must be accepted with certain reservations in the absence of a spectrophotometric examination of the calculus. 